\title{
Transient safety assessment and risk mitigation strategy of a hydroelectric generation system
}

Key Laboratory of Agricultural Soil and Water Engineering in Arid and Semiarid Areas, Ministry of Education, Northwest A\&F University, Shaanxi Yangling 712100, P. R. China

Lancaster University Renewable Energy Group and Fluid Machinery Group, Engineering Department, Lancaster University, Lancaster UK

Corresponding author: Diyi Chen

Telephone: 086-181-6198-0277

E-mail: diyichen@,nwsuaf.edu.cn

Abstract: Transient safety assessment of hydroelectric generation systems is a major challenge for engineers specializing in hydropower stations worldwide. This includes two key scientific issues: the dynamic risk quantification in multi-factors coupling process, and the indices identification with high contributions on system stability. This paper presents a new flexible, rapid and affordable dynamic safety assessment methodology for a hydroelectric generation system. Based on the fuzzy-entropy comprehensive evaluation method, the dynamic safety level of the system is estimated by means of probability and the influence contributions of assessment indices on risk operations of the hydroelectric generation system are also obtained. Moreover, some risk mitigation and maintenance strategies are finally discussed to reduce dual losses of operation and maintenance in hydropower stations. The methodology is implemented and validated in an existing hydropower station aiming at a start-up transient process, which is beneficial to risk warning and maintenance strategy enhancement. In addition the presented methodology in this paper is not only applied in the start-up transient process 
but is also promisingly and appropriate for other large fluctuation transient processes.

Keywords: hydroelectric generation system; dynamic safety assessment; transient analysis; risk mitigation; maintenance strategy

\section{Introduction}

The world energy industry is confronted with dual pressure of economic growth and environmental protection, which drives the transformation of renewable energy development [1-3]. Hydropower, as a clear energy, is becoming of interest globally by governments and society due to its reliability, flexibility and affordable expenses [4-7]. A 2017 Energy Report estimates that the world average hydroelectric generation reached 3930 kilowatt hours, currently supplying $16 \%$ of world total electricity and $68 \%$ of renewable electricity capacity [8]. The 2018 IHA Report highlights the importance of hydropower in electricity generation, and its worldwide distribution and potential development are shown in Fig. 1 [9]. The International Renewable Energy Agency (IRENA) predicts that the world hydropower capacity will reach 2200 gigawatts by 2030 [10]. Thus, hydropower shows a great potential and thus it is of a significant importance and interest to solve the problem of the energy shortage. 


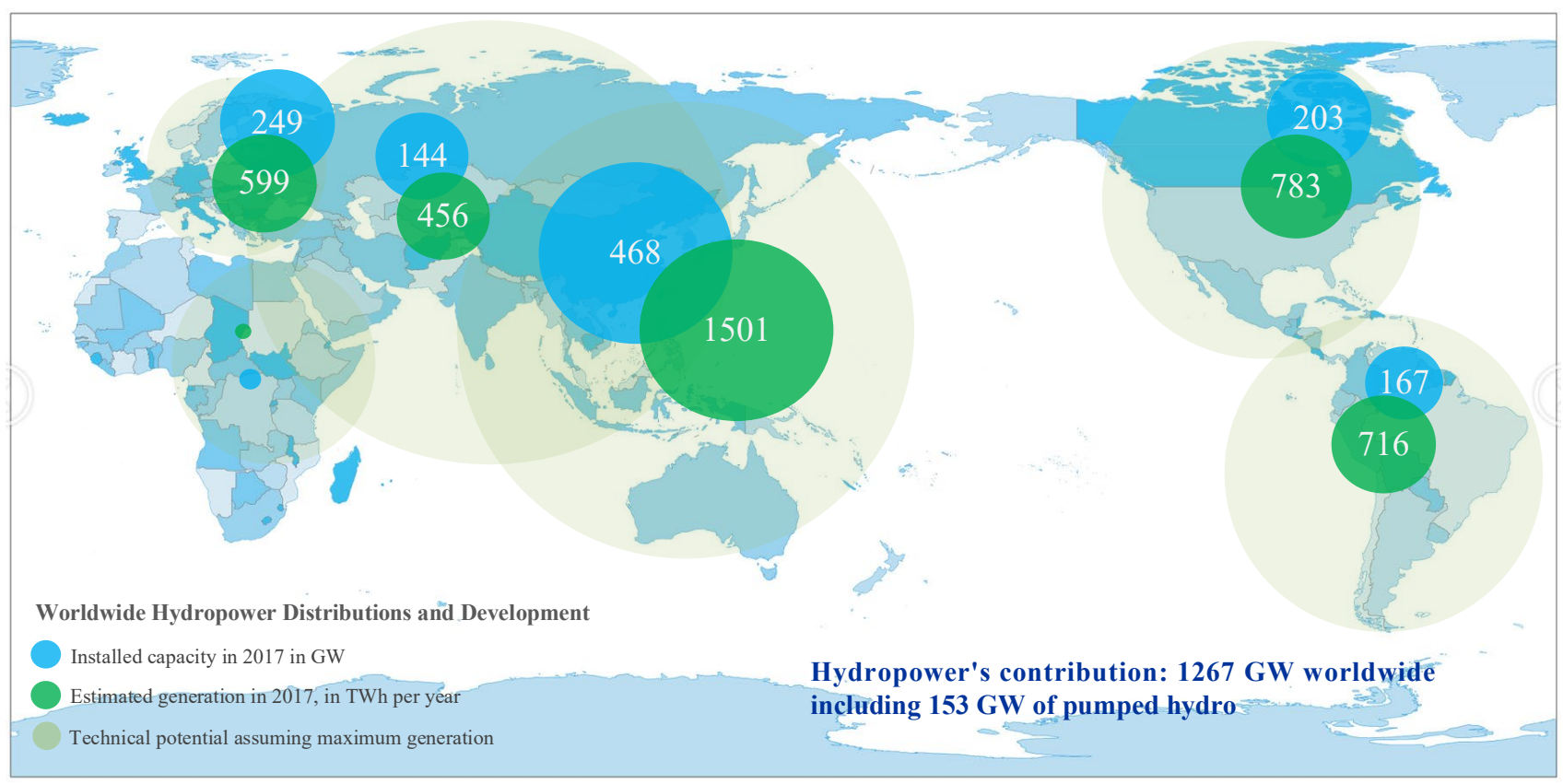

Fig. 1 Worldwide hydropower distributions and potential development [9].

Hydroelectric generation system (HGS) is a hydraulic, mechanical and electrical coupling facility, which is composed of generating unit, penstock system and governing device [11-14]. Under the influence of load disturbances, the HGS faces frequent dynamic state transitions (also called transient processes) with the increase of large capacity generating unit [15-19]. This causes different degrees of components' faults such as piping breaking and abnormal swing of rotor [20-24]. In practice there is an enormous challenge for efficient operation, fault prevention and maintenance forecast in hydropower stations [25-28]. Hence, it is an urgent and important task to assess the dynamic safety of HGSs. To date, some research scholars have attempted to study the HGS's safety from the perspective of independent subsystems like hydraulic subsystem, mechanical subsystem and electrical subsystem, whereas such an approach ignores the nonlinear coupling between subsystems. Additionally, the current method is based on the static HGS, which cannot accurately quantify the dynamic risks of HGSs.

Fuzzy comprehensive evaluation method (FCE) and dynamic entropy-weight method herein are 
developed to assess the transient safety of HGSs. FCE is a powerful condition assessment method by means of the theory of fuzzy mathematics, which gives a global evaluation of uncertain system with multiple internal-external factors [29-31]. The entropy-weight method is used to measure the degree of indices' variations, which has been widely applied in various research fields. In this paper, an enhanced dynamic entropy-weight method is proposed to implement the dynamic FCE [32-34]. The dynamic FCE presented in this work realizes the dual estimations of indices' dynamic contributions on system stability and the dynamic safety level during the transient process.

The target of this paper is assessing the transient safety of nonlinear HGSs and its innovation could be summarized in three main points. First, a novel enhanced dynamic fuzzy-entropy evaluation method, combining FCE with dynamic entropy-weight method, is presented to enable the transient safety assessment. It could be stated that the dynamic FCE presented in this work can not only implement the safety assessment of HGSs, but also be applied in other nonlinear complex systems. Second, from the point of view of the entire system, this paper establishes a new safety assessment framework of a hydraulic-mechanical-electrical coupling HGS. This framework aims at the large fluctuation transient processes, such as start-up, shut-down and load rejection, which also realizes the transition from static to dynamic assessment. Third, this paper seeks to provide some corresponding risk mitigation strategies and maintenance enhancement suggestions to improve greatly the dynamic stability of HGS as well as to reduce the operation loss and maintenance loss in hydropower stations.

\section{Transient characteristics of hydroelectric generation system}

The hydroelectric generation system (HGS) efficiently uses the hydropower to generate electricity and transmits the electricity to power grid, thus it is very important to ensure and evaluate its safety 
and operation in steady states and especially in transient processes. A universal HGS is composed of reservoir, piping system, surge tank, hydro-turbine, generator and control system, as shown in Fig. 2.

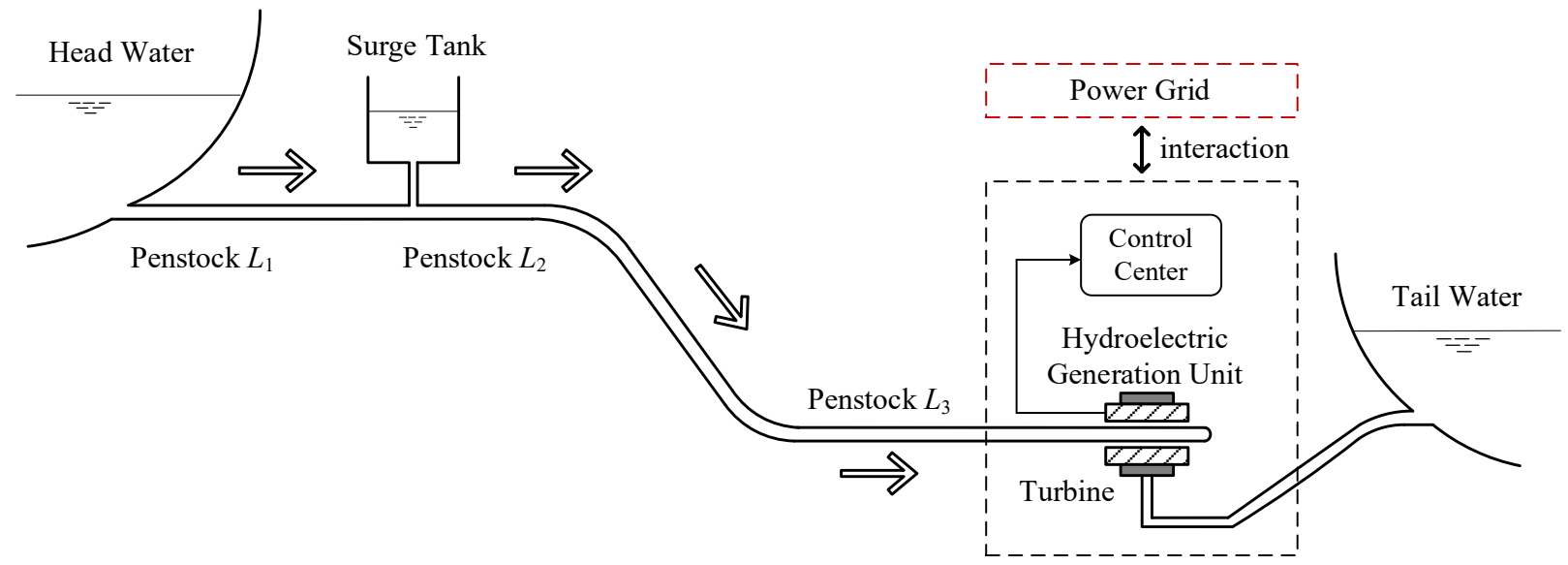

Fig. 2 A structure of a hydroelectric generation system.

In this work, we focus on the risk assessment of HGS in start-up transient process since it is one of the most commonly occurring operating process. During the start-up transient process, the guide vane opening increases in terms of three-segment law performed as in Fig. 3. This results in the pressure pulsation of the flow in pipes and the considerable increase of turbine torque, which greatly deteriorates the safety of HGS.

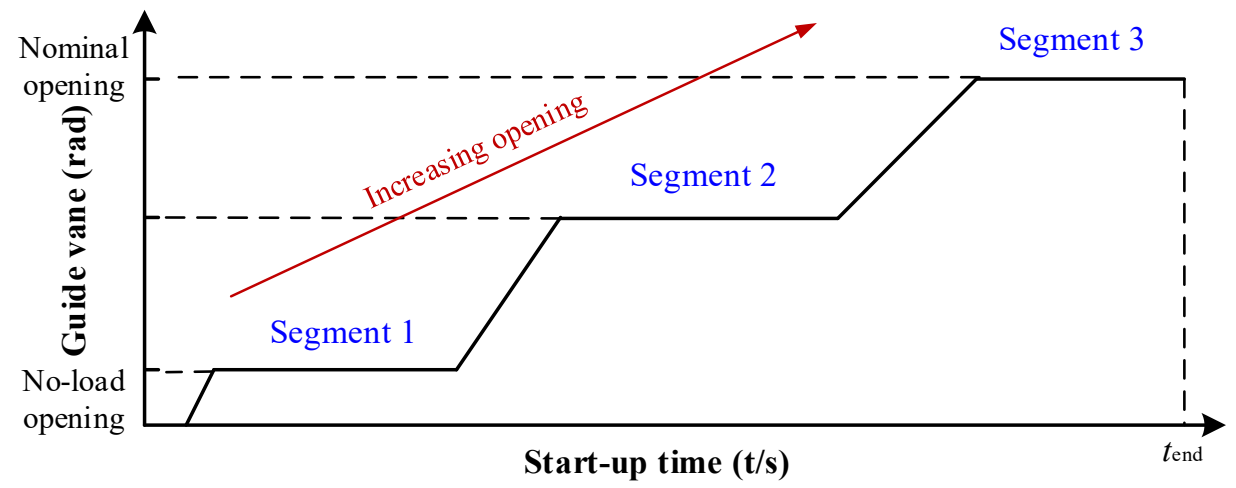

Fig. 3 The three-segment opening law of guide vane in the start-up transient process.

Based on Fig. 3, the dynamic characteristics of HGS in the start-up transient process is expressed by the turbine torque $M_{t}$ and the pipe flow $Q$, i.e., 


$$
\left\{\begin{array}{l}
M_{t}=M_{t}(H, n, y) \\
Q=Q(H, n, y)
\end{array},\right.
$$

where $H, n$ and $y$ denote the hydro-turbine head, the hydro-turbine speed and the guide vane opening, respectively.

In light of ref. [19], Eq. (1) can be further obtained as:

$$
\left\{\begin{array}{l}
Q=\frac{\omega r_{0}^{2}+\frac{9.8 \eta H}{\omega}}{\frac{\operatorname{ctg} \alpha}{2 \pi b_{t}}+r_{0} \frac{\operatorname{ctg} \beta_{0}}{F}} \\
M_{t}=Q\left[\left(\frac{\operatorname{ctg} \alpha}{2 \pi b_{t}}+r_{0} \frac{\operatorname{ctg} \beta_{0}}{F}\right) Q-\omega r_{0}^{2}\right]
\end{array},\right.
$$

where $\omega, \alpha, b_{t}, F, r_{0}$ and $\beta_{0}$ denote the generator rotor speed, the guide vane discharge angle, the guide vane height, the runner outlet area, the runner intermediate flow surface radius and the runner intermediate flow surface angle, respectively.

\section{Methodology}

This paper presents an enhanced dynamic fuzzy-entropy evaluation method aiming at assessing the HGS in large fluctuation transient process. This innovative method effectively overcomes the static performance estimations in previous conventional approaches, and its implementation is conducive to risk warning and maintenance schedule enhancement in hydropower stations.

To manage the shortcoming of subjective weights used in participation estimations of dynamic assessment indices, a precise entropy weights method is employed. For a transient HGS, nineteen assessment indices (X1 X19) and three comments of safety levels (Stable, Unstable and Unacceptable) are extracted and their change rules are listed in Table 1. The stable comment means that the HGS is in a normal working state within unavoidable vibrations and noises. The unstable comment is defined 
as the relative harsh operating condition that is able to have negative impact on operators and the residual operating life of HGS. The unacceptable comment refers to the immediate risk accident, causing operation loss and maintenance loss in hydropower stations.

Table 1 Assessment principle for indices of the HGS

\begin{tabular}{|c|c|c|c|c|c|c|c|}
\hline Comment level & $\begin{array}{c}\mathrm{X} 1, \mathrm{X} 2, \\
\mathrm{X} 3\end{array}$ & $\begin{array}{l}\text { X4, X5 } \\
\text { X6, X7 }\end{array}$ & $\mathrm{X} 8, \mathrm{X} 9$ & $\begin{array}{l}\text { X10, X11, } \\
\text { X13, X14, } \\
\text { X19 }\end{array}$ & $\mathrm{X} 12, \mathrm{X} 15$ & $\mathrm{X} 16$ & $\mathrm{X} 17, \mathrm{X} 18$ \\
\hline Stable (S) & $0 \sim 54$ & $0 \sim 280$ & $0 \sim 350$ & $0 \sim 100$ & $0 \sim 70$ & $0 \sim 35$ & $0 \sim 80$ \\
\hline Unstable (B) & $74 \sim 108$ & $320 \sim 460$ & $400 \sim 525$ & $120 \sim 200$ & $90 \sim 140$ & $45 \sim 70$ & $100 \sim 160$ \\
\hline Unacceptable $(\mathrm{P})$ & $>108$ & $>500$ & $>575$ & $>220$ & $>160$ & $>80$ & $>180$ \\
\hline
\end{tabular}

- Indices X1 X3 denote inlet pressure of spiral casing (kPa), pressure of head cover $(\mathrm{kPa})$, and inlet pressure of draft pipe $(\mathrm{kPa})$. Indices $\mathrm{X} 4 \sim \mathrm{X} 7$ are swing of upper guide bearing in $\mathrm{X}$-direction $(\mu \mathrm{m})$, swing of upper guide bearing in y-direction $(\mu \mathrm{m})$, swing of lower guide bearing in X-direction $(\mu \mathrm{m})$, and swing of lower guide bearing in $\mathrm{y}$-direction $(\mu \mathrm{m})$. Indices $\mathrm{X} 8 \sim \mathrm{X} 9$ are swing of hydraulic guide bearing in $\mathrm{X}$-direction $(\mu \mathrm{m})$, and swing of hydraulic guide bearing in y-direction $(\mu \mathrm{m})$. Indices X10 X12 refer to vibration of upper bracket in X-direction $(\mu \mathrm{m})$, vibration of upper bracket in y-direction $(\mu \mathrm{m})$, and vibration of upper bracket in $\mathrm{z}$-direction $(\mu \mathrm{m})$. Indices X13 X16 represent vibration of lower bracket in x-direction $(\mu \mathrm{m})$, vibration of lower bracket in y-direction $(\mu \mathrm{m})$, vibration of lower bracket in zdirection $(\mu \mathrm{m})$, and horizontal vibration of stator frame $(\mu \mathrm{m})$. Indices X17 X19 are vibration of head cover in Xdirection $(\mu \mathrm{m})$, vibration of head cover in y-direction $(\mu \mathrm{m})$, and vibration of head cover in z-direction $(\mu \mathrm{m})$.

It is expected to mitigate vibrations, swings and pressure pulsation in actual operation of hydropower station, thus all selected $m$ assessment indices belong to the inverse index. If there are $n$ comments of safety levels, the normalization equation for the data of $m$ assessment indices at transient time $t\left(t=\left[0, t_{\text {end }}\right]\right)$ is expressed as:

$$
r_{i j}(t)=\frac{\max x_{i j}(t)-x_{i j}(t)}{\max x_{i j}(t)-\min x_{i j}(t)}, i=1,2, \ldots, m \text { and } j=1,2, \ldots, n
$$

where $r_{i j}(t)$ is the normalization set of inverse index at transient time $t . \max x_{i j}(t)$ and $\min x_{i j}(t)$ denote the maximum and minimum values in allowing interval (see Table 1), respectively. $x_{i j}(t)$ is the actual data of assessment indices at transient time $t$.

Based on the entropy theory, then the entropy value of assessment index $i$ at transient time $t$ is obtained as:

$$
H_{i}(t)=\lambda \sum_{j=1}^{n} r_{i j}(t) \ln r_{i j}(t), i=1,2, \ldots, m
$$


where the variable $\lambda=-\frac{1}{\ln n}$.

If the normalized index $r_{i j}(t)=0$, then it yields:

$$
r_{i j}(t) \ln r_{i j}(t)=0
$$

As a result, the entropy weight set of $m$ assessment indices at transient time $t$, i.e. $W(t)=\left\{\omega_{1}(t), \omega_{2}(t), \ldots, \omega_{m}(t)\right\}$, is calculated by the following equation.

$$
\left\{\begin{array}{l}
\omega_{i}(t)=\frac{1-H_{i}(t)}{m-\sum_{i=1}^{m} H_{i}(t)}, \omega_{i} \in[0,1] . \\
\sum_{i=1}^{m} \omega_{i}(t)=1
\end{array}\right.
$$

To ensure that the assessment indices (X1 X19) meet $U=\left\{u_{1}, u_{2}, \ldots, u_{m}\right\}$ and comments of safety levels (Stable-S, Unstable-B and Unacceptable-P) satisfy $V=\left\{v_{1}, v_{2}, \ldots, v_{n}\right\}$. Based on classifications of indices and the related change rules in Table 1, the fuzzy membership function of nineteen assessment indices is divided into two types, as shown in Fig. 4. The shape of fuzzy membership function of indices $(\mathrm{X} 1, \mathrm{X} 2)$ are similar to index $\mathrm{X} 3$, and that of indices (5 19) are similar to index $\mathrm{X} 4$. That is, based on the maximum and minimum of indices (X1 X19) and their corresponding fuzzy membership functions could be finally determined.

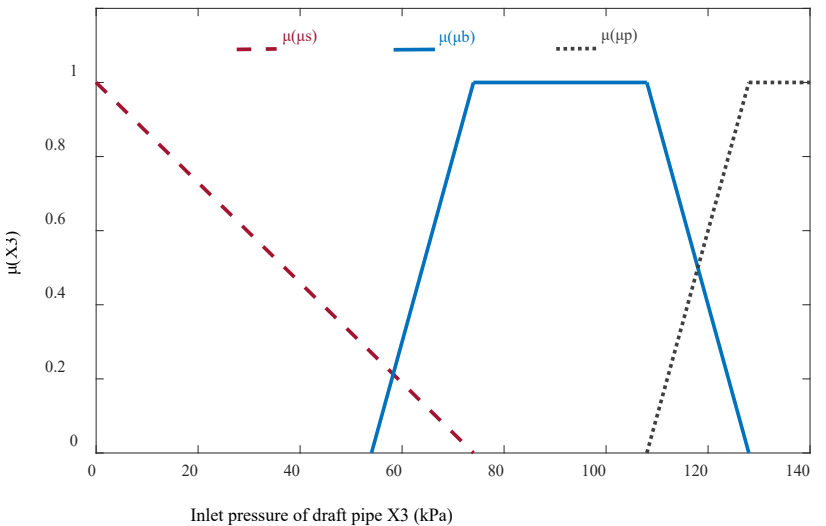

(a) Inlet pressure of draft pipe (Index X3)

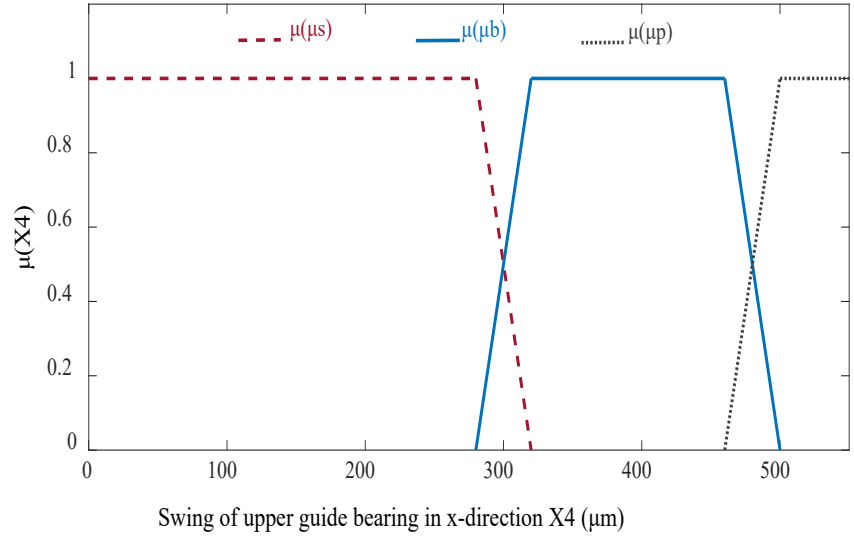

(b) Swing of upper guide bearing in x-direction (Index X4)

Fig. 4 Two types of examples of fuzzy membership functions for assessment indices of the HGS in 
start-up transient process.

Based on Fig. 4, the fuzzy membership functions of inlet pressure of draft pipe (X3) and swing of upper guide bearing in X-direction (X4) at transient time $t$ are respectively obtained in Eq. (7) and Eq. (8). Besides, the other fuzzy membership functions of assessment indices are performed in Appendix 1.

$$
\begin{aligned}
& \mathrm{X} 3: \mu_{i j}\left(V_{k}\right)_{t}=\left\{\begin{aligned}
\mu(\mu s)=\left\{\begin{array}{l}
-\frac{p}{74}+1, \quad p \in(-\infty, 74] \\
0, \quad \text { others }
\end{array}\right. \\
\mu(\mu b)= \begin{cases}\frac{p}{20}-\frac{27}{10}, \quad p \in[54,74) \\
1, \quad p \in(74,108] \\
-\frac{p}{20}-\frac{32}{5}, & p \in(108,) \\
0, & \text { others }\end{cases} \\
\mu(\mu p)= \begin{cases}0, & p \in(-\infty, 108] \\
\frac{p}{20}-\frac{27}{5}, & p \in(108,128] \\
1, & \text { others }\end{cases}
\end{aligned}\right. \\
& \mathrm{X} 4: \mu_{i j}\left(V_{k}\right)_{t}=\left\{\begin{array}{l}
\mu(\mu s)=\left\{\begin{array}{l}
1, \quad p \in(-\infty, 280] \\
-\frac{p}{40}+8, \quad p \in(280,320] \\
0, \quad \text { others }
\end{array}\right. \\
\qquad(\mu b)= \begin{cases}\frac{p}{40}-7, \quad p \in(280,320] \\
1, \quad p \in(320,460] \\
-\frac{p}{40}+\frac{25}{2}, \quad p \in(460,500] \\
0, \quad \text { others }\end{cases} \\
\mu(\mu p)= \begin{cases}0, & p \in(-\infty, 460] \\
\frac{p}{40}-\frac{23}{2}, & p \in(460,500] \\
1, & \text { others }\end{cases}
\end{array}\right.
\end{aligned}
$$

where $\mu(\mu s), \mu(\mu b)$ and $\mu(\mu p)$ are the fuzzy membership functions with respect to Stable 
comment, unstable comment and unacceptable comment, respectively.

Subsequently, the fuzzy relationship assessment matrix regarding nineteen indices and three comments of safety levels at time $t$ yields:

$$
\left(R_{t_{-} i j}\right)_{m \times n}=\left[\begin{array}{ccc}
\mu_{11}\left(u_{1}, v_{1}\right)_{t} & \mu_{12}\left(u_{1}, v_{2}\right)_{t} & \mu_{13}\left(u_{1}, v_{3}\right)_{t} \\
\mu_{21}\left(u_{2}, v_{1}\right)_{t} & \mu_{22}\left(u_{2}, v_{2}\right)_{t} & \mu_{23}\left(u_{2}, v_{3}\right)_{t} \\
\mu_{31}\left(u_{3}, v_{1}\right)_{t} & \mu_{32}\left(u_{3}, v_{2}\right)_{t} & \mu_{33}\left(u_{3}, v_{3}\right)_{t} \\
\mu_{41}\left(u_{4}, v_{1}\right)_{t} & \mu_{42}\left(u_{4}, v_{2}\right)_{t} & \mu_{43}\left(u_{4}, v_{3}\right)_{t} \\
\ldots & \ldots & \ldots \\
\mu_{17 \_1}\left(u_{17}, v_{1}\right)_{t} & \mu_{17_{-2}\left(u_{17}, v_{2}\right)_{t}} & \mu_{17 \_}\left(u_{17}, v_{3}\right)_{t} \\
\mu_{18{ }_{1} 1}\left(u_{18}, v_{1}\right)_{t} & \mu_{18_{-2}\left(u_{18}, v_{2}\right)_{t}} & \mu_{18 \_3}\left(u_{18}, v_{3}\right)_{t}
\end{array}\right]_{18 \times 3}
$$

Combining Eq. (6) and Eq. (9), the fuzzy-entropy comprehensive assessment matrix at time $t$ is expressed as:

$$
A_{t}=\left(W_{t}\right)_{3 \times 18} \cdot\left(R_{t_{-} i j}\right)_{18 \times 3}=\left\{A_{1 t}, A_{2 t}, A_{3 t}\right\} .
$$

According to maximum membership principle, the adaptive safety level of HGS at time $t$ is $A_{\max \mid t=t}$ and meets the condition of $A_{\max \mid t=t}, A_{\max \mid t=t} \in A_{t}$. Thus, the adaptive comment set of safety levels during the whole start-up transient process is finally calculated as:

$$
A_{a}=\left\{A_{\max \mid t=1}, A_{\max \mid t=2}, \ldots, A_{\max \mid t t_{\text {end }}-1}, A_{\max \mid t=t_{\text {end }}}\right\} .
$$

However, considering both unacceptable comment and unstable comment threaten the safety operation of the HGS, we define a modified comment set of safety levels $A_{c}$ that comprehensively takes into account the total probability of the unstable and unacceptable comments.

$$
A_{c}=\left\{A_{\mathrm{B}+\mathrm{P} \mid t=1}, A_{\mathrm{B}+\mathrm{P} \mid t=2}, \ldots, A_{\mathrm{B}+\mathrm{P} \mid t=t_{\text {end }}-1}, A_{\mathrm{B}+\mathrm{P} \mid t=t_{\text {end }}}\right\} .
$$

The global methodology implemented in this paper is demonstrated in Fig.5. 


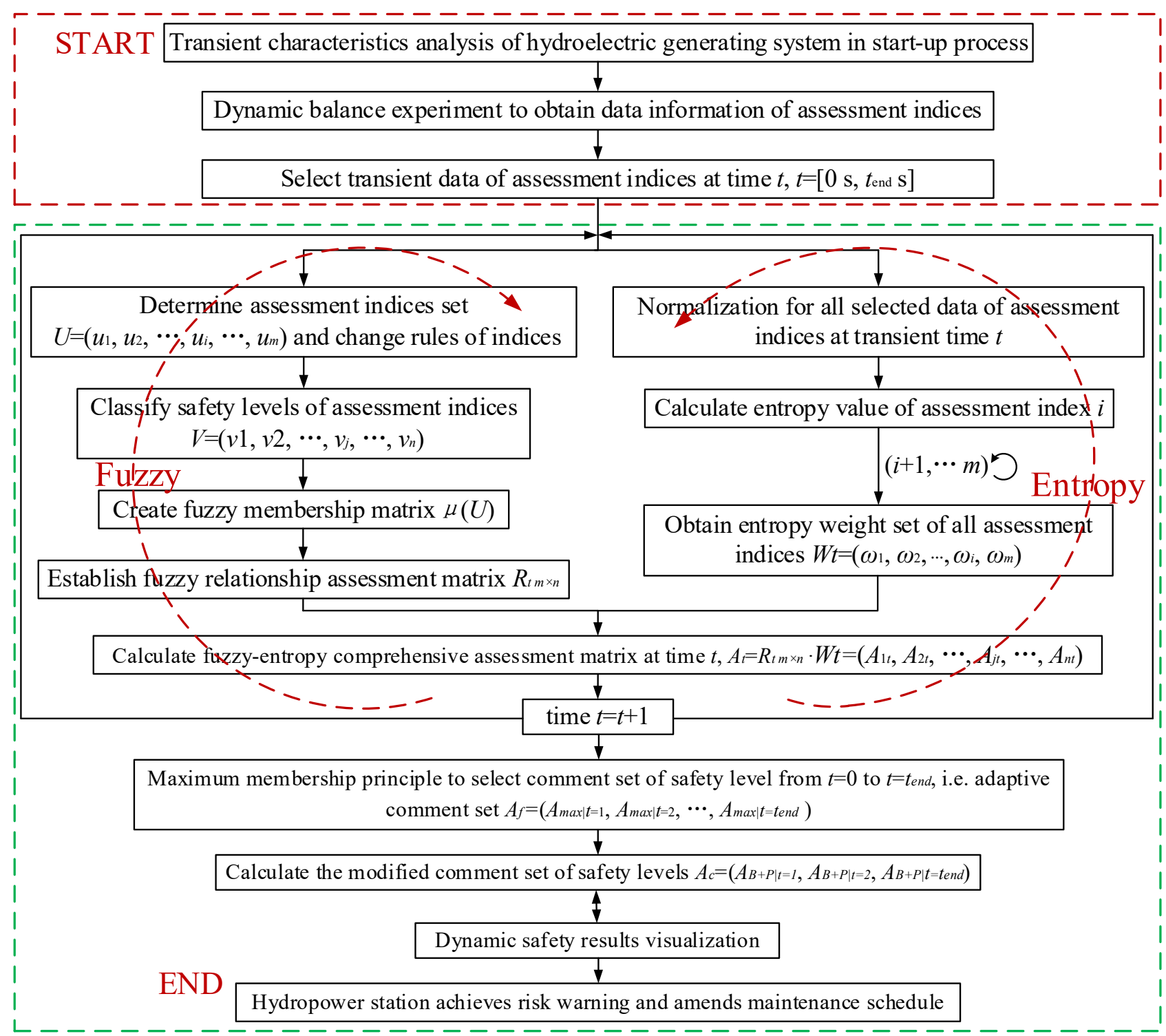

Fig. 5 Global methodology of dynamic safety assessment of hydroelectric generating system.

The calculation process plan is concluded and described in the following steps:

(1) Carry out dynamic balance experiments on the basis of an existing hydropower station to obtain the start-up transient data of HGS (i.e. indices X1 X19 listed in Table 1). To improve the data reliability, use the analysis results of transient performance characteristics of the HGS to identify and diminish outlier in data.

(2) Selecting thirteen monitoring times $\left(t=t_{1} \sim t_{\text {end }}\right)$ referring to the transient time within increasing loads 10MW, 20MW, 30MW and till 130MW to collect data signals of multiple sensors. According to 
time priority, evaluate orderly the safety properties of HGS from time $t_{1}$ to time $t_{\text {end }}$.

(3) To enable the fuzzy-entropy analysis, first determine nineteen assessment indices (i.e. X1 X19) and three comments of safety levels (i.e. Stable, Unstable and Unacceptable) defined respectively as $U=\left\{u_{1}, u_{2}, \ldots, u_{m}\right\}$ and $V=\left\{v_{1}, v_{2}, \ldots, v_{n}\right\}$. In light of the change rules in Table 1 , the fuzzy membership function $\mu(V)_{t_{1} \sim t_{\text {end }}}$ and fuzzy relationship assessment matrix $\left(R_{m \times n}\right)_{t_{1} \sim t_{\text {end }}}$ at different times are respectively obtained as equations $(7,8)$ and equation (9).

(4) Calculating the entropy values of normalized assessment indices at the time interval $t=\left[t_{1}\right.$, $\left.t_{\text {end }}\right]$, and subsequently deducing the corresponding entropy weight set $W(t)$ in light of equation (6).

(5) Creating the fuzzy-entropy comprehensive assessment matrices $A_{t 1} \sim A_{\text {tend }}$ at different times that can be defined by the product between fuzzy relationship assessment matrix $\left(R_{m \times n}\right)_{t_{1} \sim t_{\text {end }}}$ and entropy weight set $W(t)$. Using maximum membership principle to select the adaptive comment set of safety levels $A_{a}=\left\{A_{\max \mid t=1}, A_{\max \mid t=2}, \ldots, A_{\max \mid t=t_{\text {end }}-1}, A_{\max \mid t t_{\text {end }}}\right\}$. Considering the dual threat of unacceptable and unstable states of the HGS, We define a modified comment set of safety levels $A_{c}=\left\{A_{\mathrm{B}+\mathrm{P} \mid t=1}, A_{\mathrm{B}+\mathrm{P} \mid t=2}, \ldots, A_{\mathrm{B}+\mathrm{P} \mid t t_{\text {end }}-1}, A_{\mathrm{B}+\mathrm{P} \mid t t_{\text {end }}}\right\}$. Finally, we visualize the transient safety assessment results of the HGS.

(6) Based on the analysis results, provide some important risk mitigation strategies and maintenance enhancement suggestions to improve greatly the dynamic safety of HGS and to reduce the losses of operation and maintenance in hydropower stations.

\section{Experiments}

\subsection{Start-up dynamic balance experiment}

To obtain assessment data of the HGS in start-up transient process, dynamic balance experiments 
are carried out based on an existing hydropower station in China. The mechanical-electric parameters information [35] and hydraulic testing conditions are listed in Table 2.

Table 2 Hydraulic-mechanical-electric information of experimental HGS in start-up transient process

\begin{tabular}{l|c|l|c}
\hline \multicolumn{4}{c}{ Mechanical-electric Parameters Information } \\
\hline Hydro-turbine type & HLS270-LJ-680 & Nominal turbine power & $267.85 \mathrm{MW}$ \\
\hline Nominal turbine head & $64 \mathrm{~m}$ & Nominal turbine flow & $460.46 \mathrm{~m}^{3} / \mathrm{s}$ \\
\hline Nominal turbine speed & $93.75 \mathrm{rpm}$ & Runaway speed & $185 \mathrm{rpm}$ \\
\hline Generator type & SF265-64/15000 & Generator capacity & $291.7 \mathrm{MVA}$ \\
\hline Stator voltage & $15750 \mathrm{~V}$ & Stator current & $10692 \mathrm{~A}$ \\
\hline Generator power factor & 0.9 & Exciting voltage & $350 \mathrm{~V}$ \\
\hline Exciting current & $1900 \mathrm{~A}$ & Nominal frequency & $50 \mathrm{~Hz}$ \\
\hline \begin{tabular}{l|l|l|l} 
Governor type \\
PpWT-200-6.3
\end{tabular} & $\begin{array}{l}\text { Main configuration } \\
\text { diameter }\end{array}$ & $200 \mathrm{~mm}$ \\
\hline $\begin{array}{l}\text { Opwer guide bearing } \\
\text { clearance }\end{array}$ & $6.3 \mathrm{MPa}$ & Servomotor stroke & $780 \mathrm{~mm}$ \\
\hline $\begin{array}{l}\text { Water guide bearing } \\
\text { clearance }\end{array}$ & $0.15 \sim 0.2 \mathrm{~mm}$ & $\begin{array}{l}\text { Upper guide bearing } \\
\text { clearance }\end{array}$ & $0.15 \sim 0.2 \mathrm{~mm}$ \\
\hline
\end{tabular}

The monitoring targets in the dynamic balance experiment are the indices X1 X19 listed in Table 1. The start-up experimental data are adopted from thirteen transient calculated conditions that refer to the transient times within the corresponding increasing active load of $10 \mathrm{MW}, 20 \mathrm{MW}, 30 \mathrm{MW}, 40 \mathrm{MW}$, 50MW, 60MW, 70MW, 80MW, 90MW, 100MW, 110MW, 120MW and 130MW. The experimental mainframes include PSTA-H vibration instrumentation and TTS216 dynamic signal instrumentation. The key phase patch is attached to the main shaft of generator. Electric eddy-current displacement sensors measure the swing of upper guide bearing in $\mathrm{x} / \mathrm{y}$-direction (X4 and $\mathrm{X} 5)$, the swing of lower guide bearing in $\mathrm{x} / \mathrm{y}$-direction $(\mathrm{X} 6$ and $\mathrm{X} 7$ ) and the swing of hydraulic guide bearing in $\mathrm{x} / \mathrm{y}$-direction 
(X8 and X9). Low-frequency shock transducers are used to monitor the horizontal/vertical vibrations of upper bracket, lower bracket, stator frame and head cover (i.e., X10 X19). Water pressure transducers measure the inlet pressure of spiral casing (X1), the pressure of head cover (X2) and the Inlet pressure of draft pipe (X3). Finally, all monitoring data of assessment indices are transmitted and analyzed by experimental mainframes. the measured vibrations and swings (X4 X19) belong to peakto-peak values. The obtained inlet pressure of spiral casing (X1) is the mean value, and the experimental pressure of head cover (X2) and the inlet pressure of draft pipe (X3) are peak-to-peak values.

The layout of supervision points in the dynamic balance experiment is performed in Fig. 6, and the monitoring data are shown in Fig. 7.

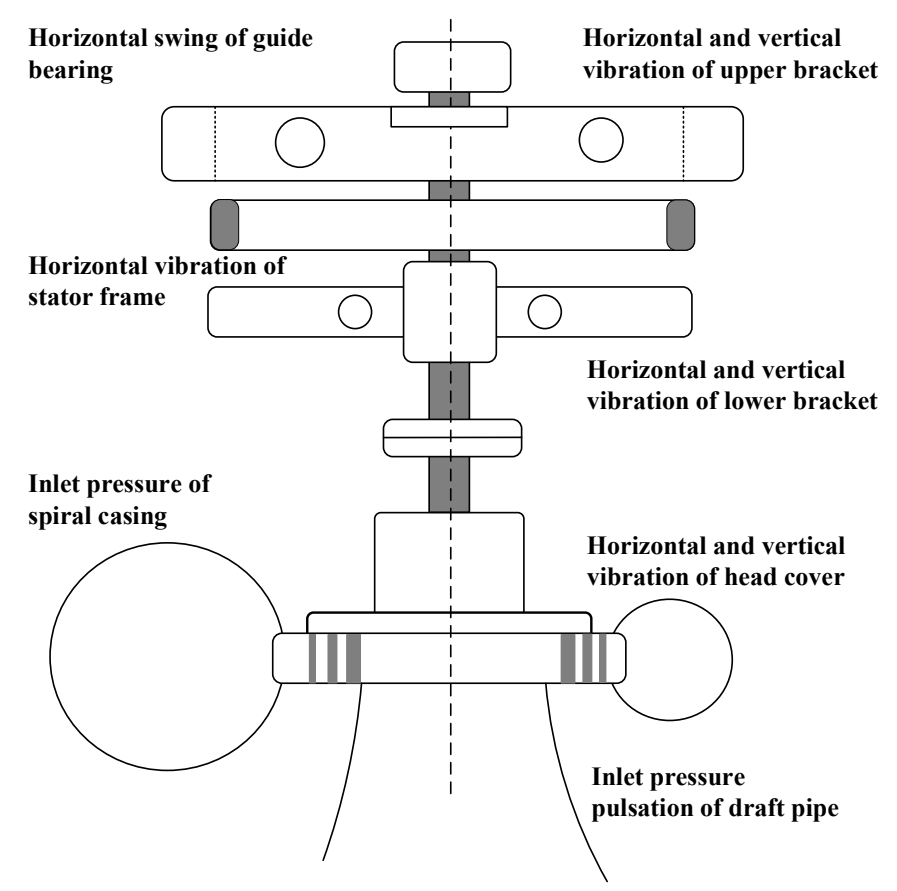

Fig. 6 Layout of supervision points of the HGS for the start-up transient process in dynamic balance experiment. 

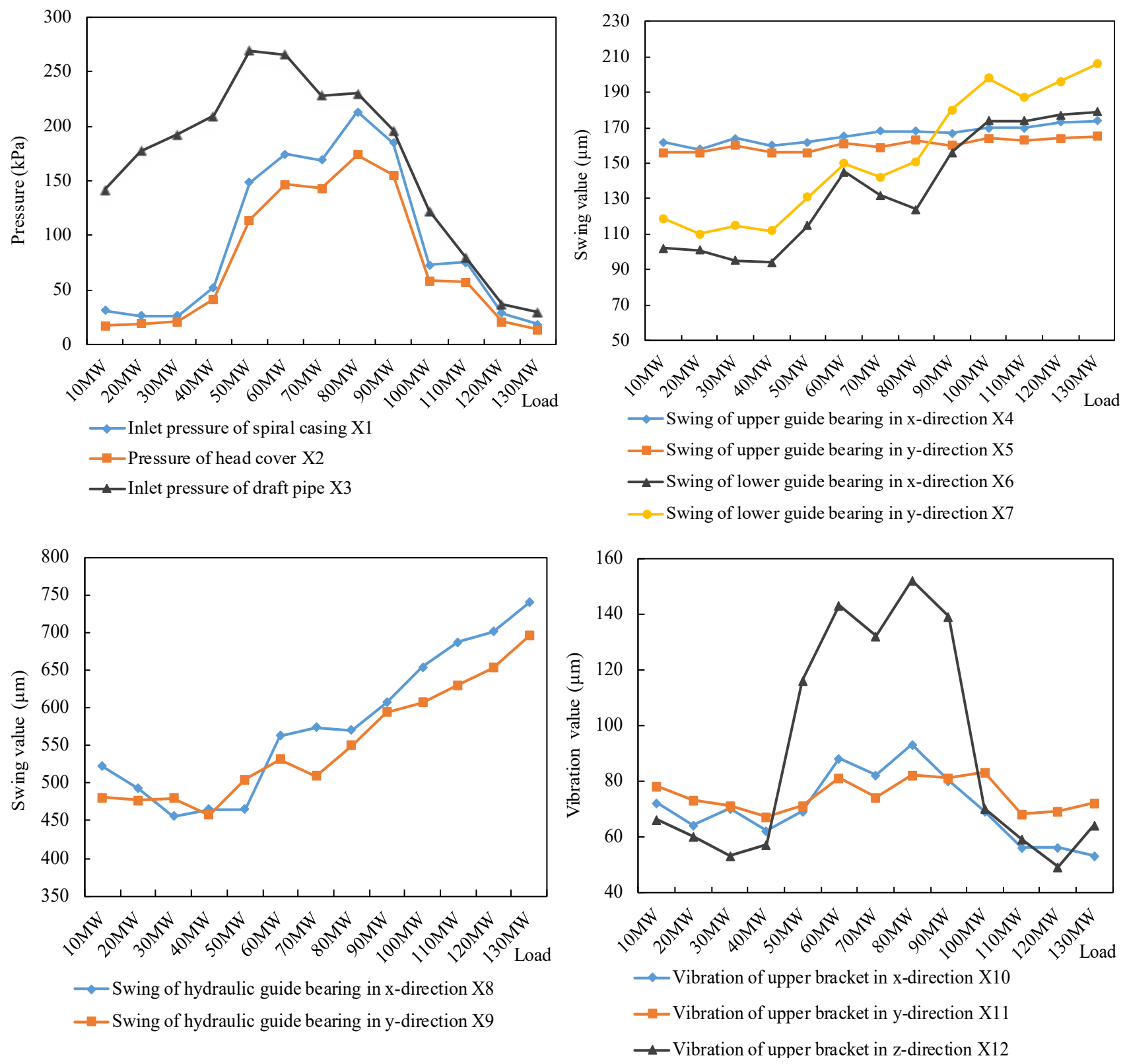

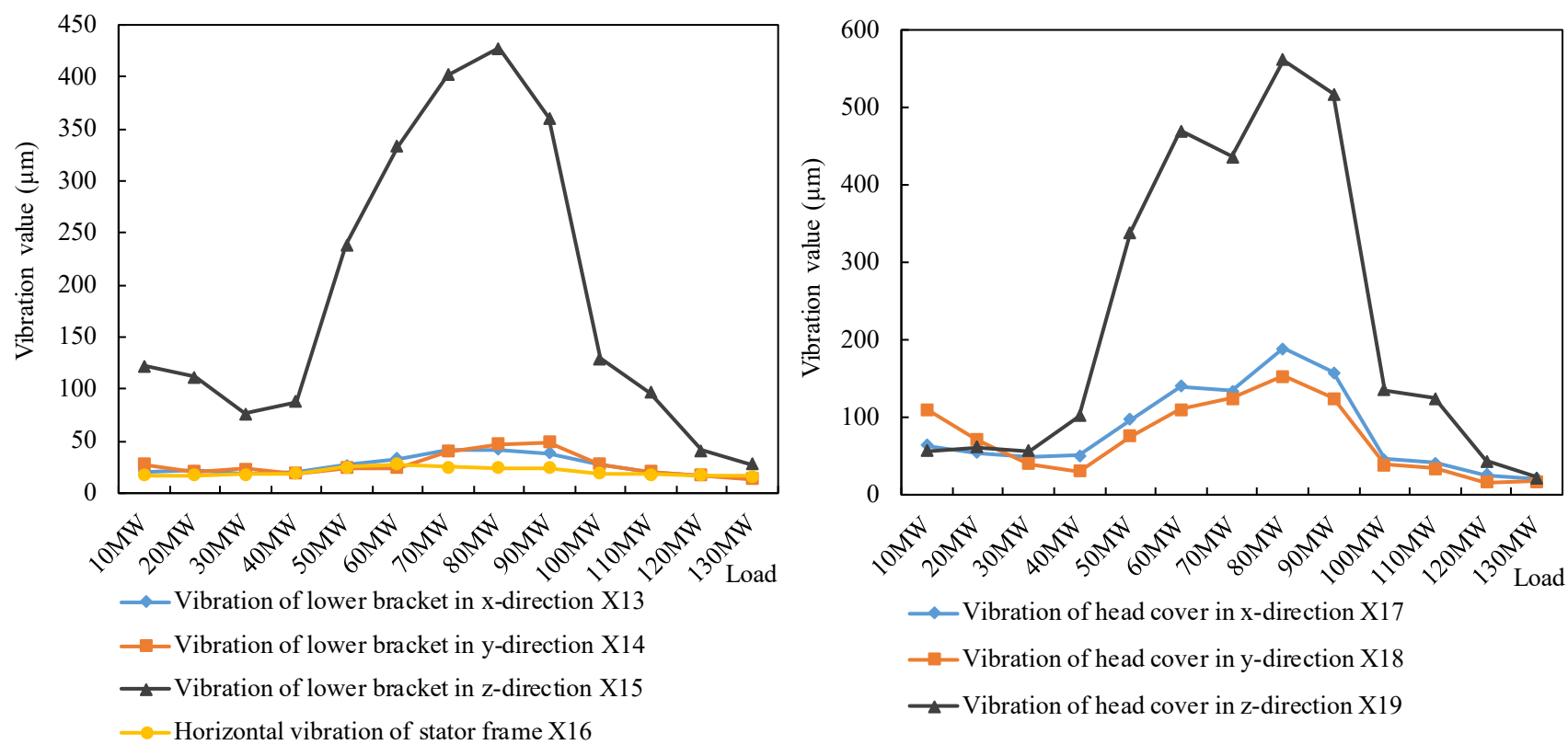

Fig. 7 Experiment data of nineteen assessment indices (X1 X19) of the HGS in start-up transient process.

\subsection{Preliminary experimental analysis}

From the experimental results in Fig. 7, it is observed that some indices exceed the allowable operating ranges (as listed in ref. [35]). Specifically, the peak values of swing of hydraulic guide bearing in x-direction (X8) and swing of hydraulic guide bearing in y-direction (X9) are roughly $710 \mu \mathrm{m}$ and $653 \mu \mathrm{m}$, respectively. This is almost more than double compared to the allowable operating value of $300 \mu \mathrm{m}$. The measured inlet pressure of draft pipe (X3) reaches the maximum of $269.5 \mathrm{kPa}$, which is obviously greater than the allowable operating value of $64 \mathrm{kPa}$. Additionally, the instability problems also exist in the inlet pressure of spiral casing (X1), the vibration of upper bracket in zdirection (X12), the vibration of lower bracket in z-direction (X15), the vibration of head cover in $\mathrm{x} / \mathrm{y} / \mathrm{z}$-direction (X17, X18 and X19).

However, it is difficult to determine the location of risk sources since half of all indices exceed their maximum allowable values. Besides, the complex internal coupling characteristics of different 
indices cannot be neglected in the transient process. For example, the small change of one index may lead to a dramatic variation of multiple indices. Therefore, to diminish the problems of vibrations, swings and fluctuations, it is necessary and urgent to conduct deep theoretical evaluations to better understand the dynamic operating quality and to eliminate confounding indices in risk determination of the HGS in start-up transient process.

\section{Dynamic safety analysis and risk mitigation}

This section aims to quantitatively analyze the safety levels of the HGS using quantized probabilities. To determine the risk sources of the HGS, the fuzzy-entropy weights of assessment indices during the full load domain (10MW 130MW) are calculated. In addition to this, the risk probability of the HGS based on the adaptive comment set $A_{a}$ and the modified comment set $A_{c}$ is investigated. In light of the safety assessment results, a number of corresponding risk mitigation strategies and maintenance enhancement suggestions to improve the transient operation of the HGS and to achieve the maximization of asset efficiency in hydropower stations are provided.

\subsection{Index contributions on HGS's risks}

To elaborate the effect of nineteen assessment indices (X1 X19) on dynamic operating quality of the HGS, Fig. 8 is presented to show the visualization results of the interaction of weights, loads and assessment indices in the start-up transient process. Also, Fig. 9 further quantifies the influence contributions of assessment indices (X1 X19) on transient risks of the HGS under different operating conditions within the load of 10MW 130MW. 


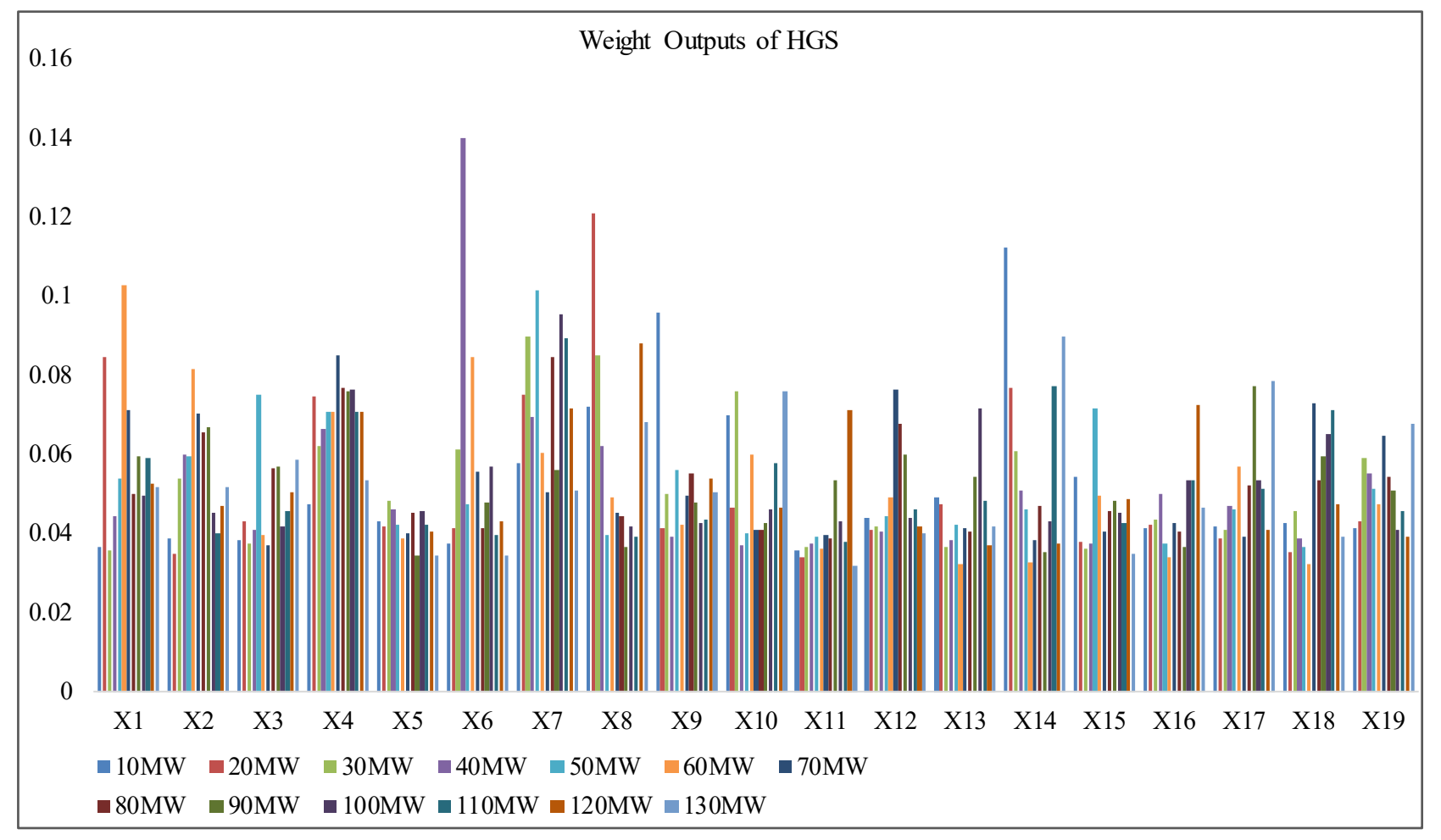

Fig. 8 Visualization results of the interaction of dynamic weights, increasing loads (10MW 130MW) and assessment indices (X1 X19) of the HGS in start-up transient process.
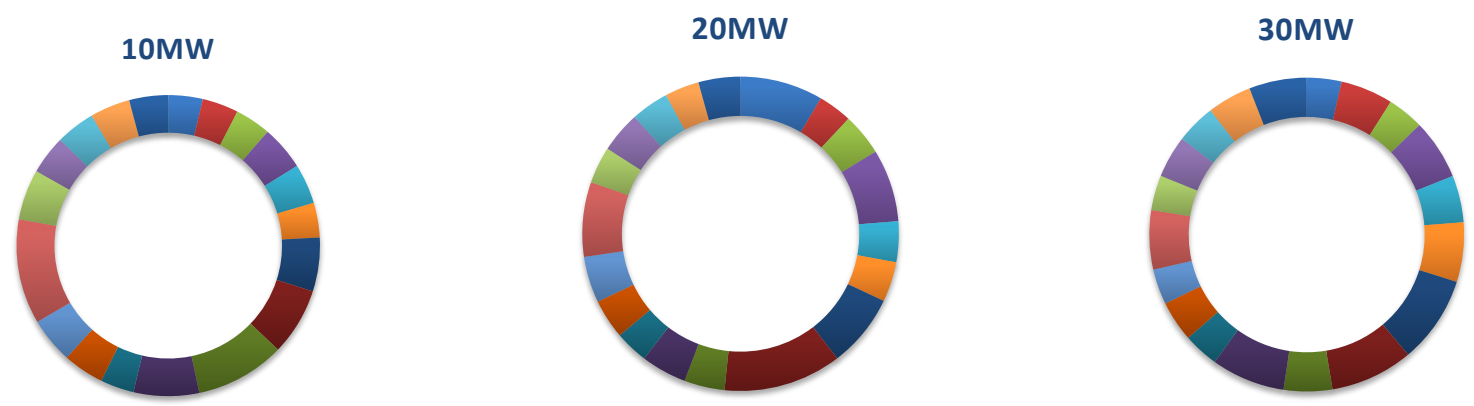

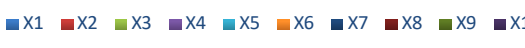

$\square \mathrm{X} 11 \backsim \mathrm{X} 12 \backsim \mathrm{X} 13 \backsim \mathrm{X} 14 \backsim \mathrm{X} 15 \square \mathrm{X} 16 \square \mathrm{X} 17 \backsim \mathrm{X} 18 \square \mathrm{X} 19$

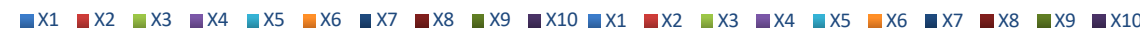

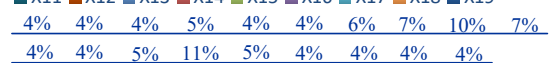
$\square \mathrm{X} 11-\mathrm{X} 12 \square \mathrm{X} 13-\mathrm{X} 14 \square \mathrm{X} 15 \square \mathrm{X} 16 \square \mathrm{X} 17-\mathrm{X} 18 \square \mathrm{X} 19$ $=\mathrm{X} 11-\mathrm{X} 12-\mathrm{X} 13-\mathrm{X} 14=\mathrm{X} 15-\mathrm{X} 16=\mathrm{X} 17-\mathrm{X} 18=\mathrm{X} 19$ \begin{tabular}{cccccccccccccccccccc}
$8 \%$ & $3 \%$ & $4 \%$ & $7 \%$ & $4 \%$ & $4 \%$ & $8 \%$ & $12 \%$ & $4 \%$ & $5 \%$ & $4 \%$ & $5 \%$ & $4 \%$ & $6 \%$ & $5 \%$ & $6 \%$ & $9 \%$ & $9 \%$ & $5 \%$ & $8 \%$ \\
\hline $3 \%$ & $4 \%$ & $5 \%$ & $8 \%$ & $4 \%$ & $4 \%$ & $4 \%$ & $4 \%$ & $4 \%$ & & $4 \%$ & $4 \%$ & $4 \%$ & $6 \%$ & $4 \%$ & $4 \%$ & $4 \%$ & $5 \%$ & $6 \%$ & \\
\hline
\end{tabular} 

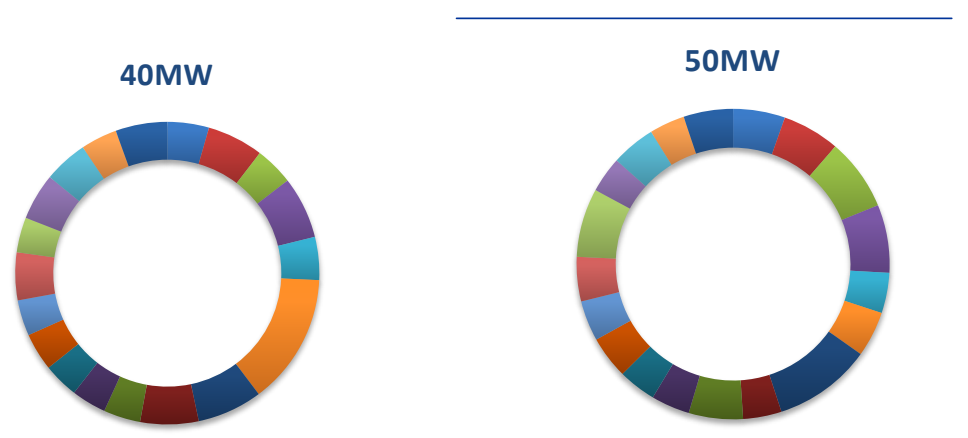

60MW

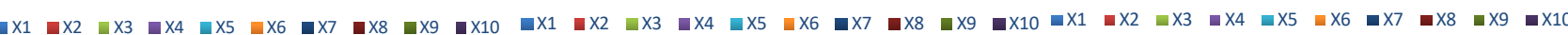

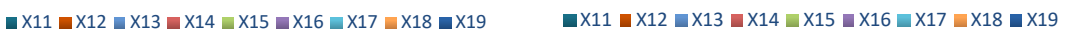

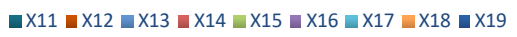

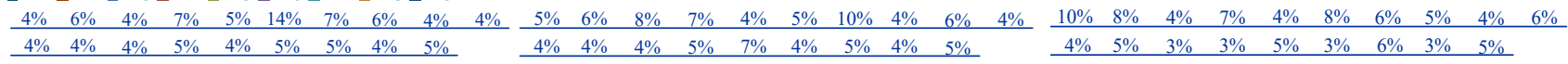
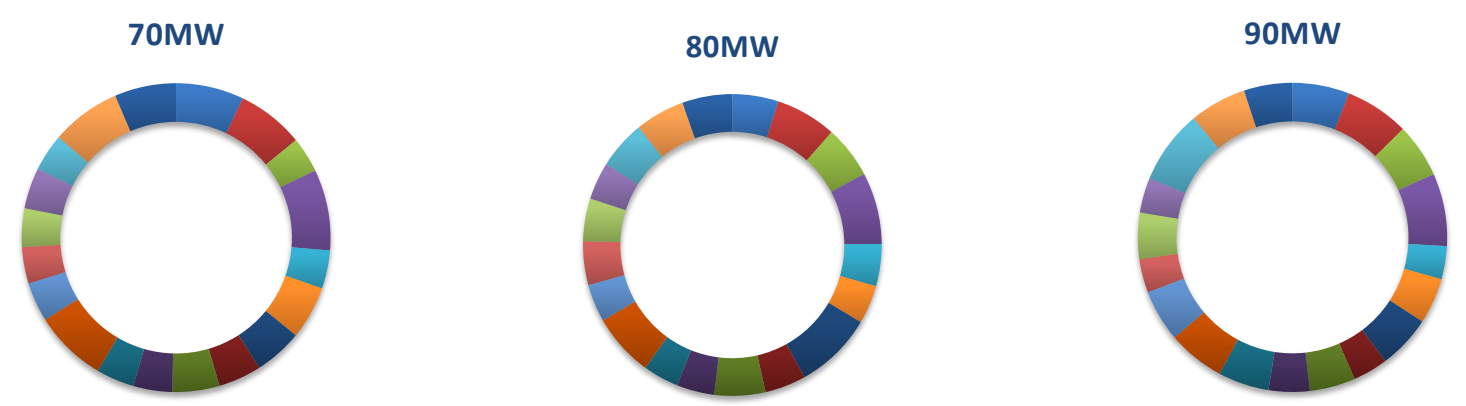

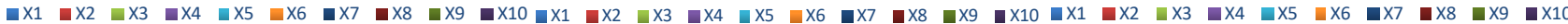

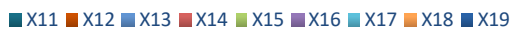

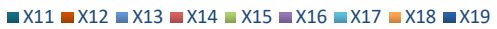

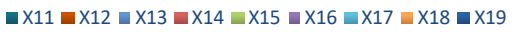

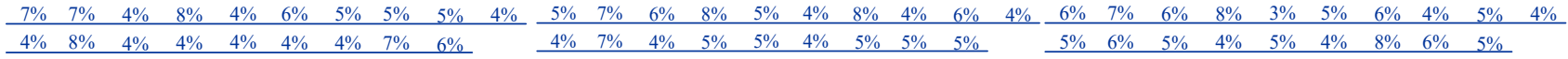
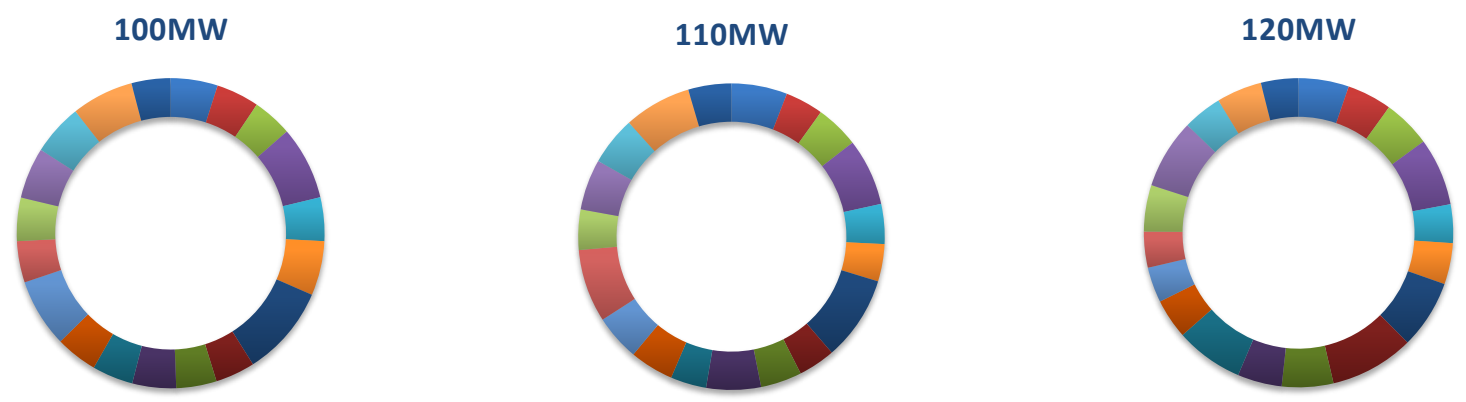

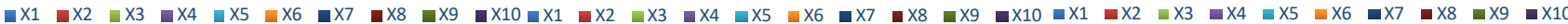

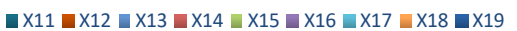

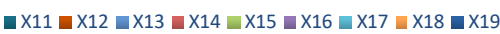
$\square \mathrm{X} 11 \square \mathrm{X} 12 \square \mathrm{X} 13 \square \mathrm{X} 14 \square \mathrm{X} 15 \square \mathrm{X} 16 \square \mathrm{X} 17 \varpi \mathrm{X} 18 \square \mathrm{X} 19$ \begin{tabular}{llllllllllllllllllllllllllllllllllll}
$5 \%$ & $5 \%$ & $4 \%$ & $8 \%$ & $5 \%$ & $6 \%$ & $10 \%$ & $4 \%$ & $4 \%$ & $5 \%$ & $6 \%$ & $4 \%$ & $5 \%$ & $7 \%$ & $4 \%$ & $4 \%$ & $9 \%$ & $4 \%$ & $4 \%$ & $6 \%$ & $5 \%$ & $5 \%$ & $5 \%$ & $7 \%$ & $4 \%$ & $4 \%$ & $7 \%$ & $9 \%$ & $5 \%$ & $5 \%$ \\
\hline
\end{tabular}

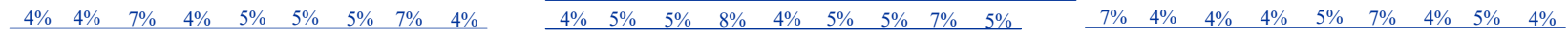

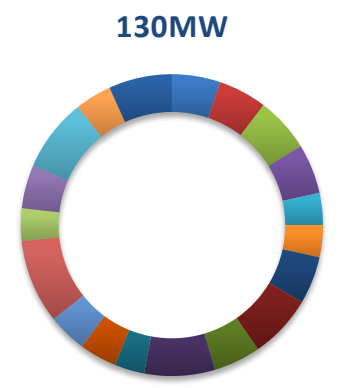

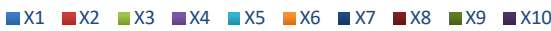

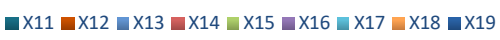

\begin{tabular}{llllllllll}
$5 \%$ & $5 \%$ & $6 \%$ & $5 \%$ & $3 \%$ & $3 \%$ & $5 \%$ & $7 \%$ & $5 \%$ & $8 \%$ \\
\hline $3 \%$ & $4 \%$ & $4 \%$ & $9 \%$ & $3 \%$ & $5 \%$ & $8 \%$ & $4 \%$ & $7 \%$ &
\end{tabular} 
Fig. 9 Quantified results of contribution weights of nineteen assessment indices (X1 X19) on HGS's risks for the start-up transient process under different operating conditions within the increasing load of 10MW, 20MW, 30MW, 40MW, 50MW, 60MW, 70MW, 80MW, 90MW, 100MW, 110MW, 120MW and 130MW.

From Fig. 8 and Fig. 9, there are different influence weights of the same index during the full load domain (10MW 130MW), implying that the indices have uncertain risk contributions on the transient HGS. for example, the time-varying weights set of index X1 is $[0.0367,0.0846,0.0357,0.0443,0.0537$, $0.1027,0.0712,0.05,0.0595,0.0494,0.0589,0.0526,0.0518]$ with respect to the increasing load from 10MW to 130MW. Moreover, for the same load condition, the indices X1 X19 develops within the mutual effect and restriction as the system load continuously increases. This means that almost all indices have a high sensibility to the risk contribution of leading indices at different dynamic risk evolution stages. Additionally, it is easy to find that the critical indices with prominent high risk contributions roughly include the inlet pressure of spiral casing (X1), swing of lower guide bearing in x-direction (X6), swing of lower guide bearing in y-direction (X7), swing of hydraulic guide bearing in X-direction (X8), swing of hydraulic guide bearing in y-direction (X9) and vibration of lower bracket in $\mathrm{y}$-direction $(\mathrm{X} 14)$.

\subsection{Transient safety assessment of HGS}

Based on equation (11), Fig. 10 presents the adaptive comment set of HGS's safety levels (i.e. $A_{a}$ ) to reflect the probabilities of stable, unstable and unacceptable operating states in the start-up transient process. Based on equation (12), the modified comment set (i.e. $A_{c}$ ) is shown in Fig. 11 to reveal the dual adverse effect of the unstable state and unacceptable state on the transient HGS. 


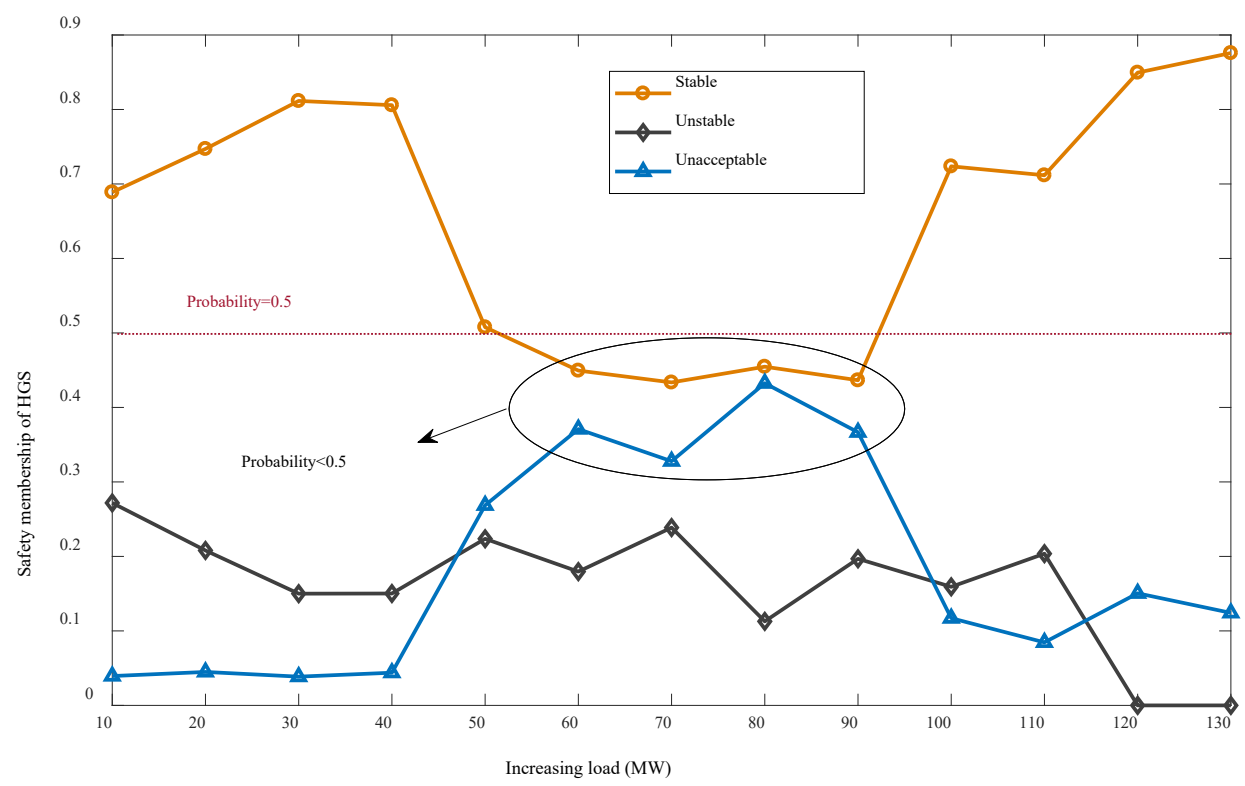

Fig. 10 Dynamic safety levels of the HGS obtained from the adaptive comment set $A_{a}$ in the start-up transient process.

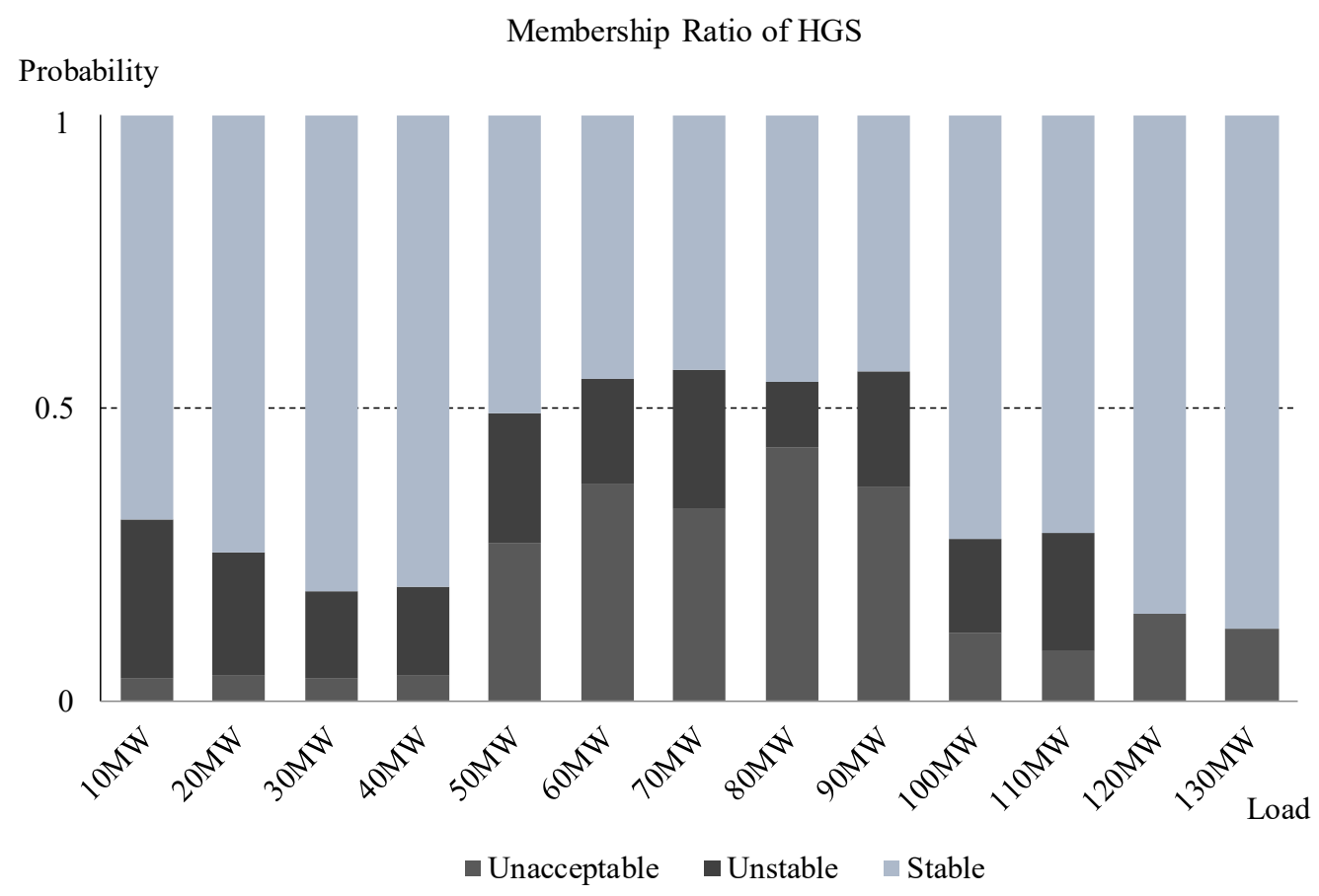

Fig. 11 Enhanced dynamic safety levels of the HGS obtained from the modified comment set $A_{c}$ in the start-up transient process.

As shown in Fig. 10, all final adaptive comments for safety levels of the transient HGS under different load conditions are judged to be stable on the basis of the maximum membership principle. 
Almost all stable probabilities of the HGS excepting the probabilities in the load interval [50MW, 90MW] are greater than 0.5. Simultaneously, it is observed that the stable probabilities are close to unstable probabilities in the load interval [50MW, 90MW]. This alerts the operators to pay more attention to the occurrence of large vibrations and loud noises or even the start-up failures. It is worth noting that the maximal unacceptable probability $(0.0394)$ occurs at the load of $10 \mathrm{MW}$, which means that the major risk is highly likely to occurs at the beginning stage of the transient process. Conversely, the maximal stable probability is 0.8893 , revealing that the HGS is able to connect to the electric power grid safely.

Fig. 11 clearly performs the total unexpected probability of unstable comment and unacceptable comment under different operating conditions within the increasing load of 10MW 130MW. The combined probability is extremely close to the value of 0.5 at the load of $50 \mathrm{MW}$, and the combined probabilities are greater than the value of 0.5 during the load range of [60MW, 90MW]. This should draw hydropower station's attention to the occurrence of instability problems during this load domain.

\subsection{Risk mitigation and maintenance strategies}

The operating target of hydropower stations is to reduce avoidable risks, to avoid additional costs of power production and to coordinate maintenance schedules of workers. All of these targets are able to be achieved by improving the HGS's safety operation in transient processes. In this research work, the above transient safety assessment results can give the guidance to the enhancements of risk mitigation strategies and maintenance strategies in hydropower stations. Correspondingly, the detailed suggestions are summarized as follows:

i) The operators should be concerned with the working condition of the HGS in the load domain 
[50MW, 90MW], monitoring timely risk indices to generate effective warning strategies to avoid failure accidents. The hydropower station develops urgent maintenance procedures to realize the goal of loss-aversion. Meanwhile, it is better for maintenance workers to pay more attention to the faults location during the next maintenance period if the warning strategies and maintenance procedures are entirely ineffective.

ii) Aiming at the situation that the high risk occurs at the early stage of the start-up transient process, it is suggested that the operating planners optimize the start-up strategy such as the optimization of guide vane law and the reduction of misoperation frequency. Additionally, the hydropower station should arrange repair plans to manage with potential adverse accidents.

iii) The final assessment comment of the HGS's dynamic operating quality is stable, although we cannot exclude the occurrence of potential unstable and unacceptable events. Based on this comment, the hydropower is able to extend the maintenance period or change its regular time-based maintenance strategy to condition-based maintenance strategy to optimize the maintenance schedule of workers and to minimize the maintenance loss.

\section{Conclusions}

This paper evaluates the transient safety quality of the HGS, providing contributions to the current international pool of dynamic safety knowledge compared with the conventional static safety assessment of HGSs. To achieve the analysis, it first develops an enhanced fuzzy-entropy evaluation approach to enable the dynamic risk quantification based on the assessment indices obtained by dynamic balance experiments and corresponding theory modifications. The calculated dynamic weights of indices reveal their influence contributions on instability of the HGS. Then finds that the 
critical indices with prominent high risk contributions for the start-up transient process roughly include the inlet pressure of spiral casing (X1), swing of lower guide bearing in X-direction (X6), swing of lower guide bearing in $\mathrm{y}$-direction (X7), swing of hydraulic guide bearing in x-direction (X8), swing of hydraulic guide bearing in y-direction (X9) and vibration of lower bracket in y-direction (X14). Additionally, the transient safety levels for the full load domain (10MW, 130MW) are successfully estimated, and the assessment results show that the final evaluation comment of safety quality for the start-up transient HGS is stable, although it cannot be excluded the potential unstable and unacceptable events. The hydropower stations will pay more attention to operating states of the HGS in the load interval [50MW, 90MW] since the stable probabilities are close to unstable probabilities. Simultaneously, the dynamic safety status at the early stage of the transient process is also required to pay special attention because the relevant maximal unacceptable probability reaches 0.0394 . Finally, aiming at the results of the quantitative calculation and qualitative analysis, it presents some corresponding responses of risk mitigation strategies and maintenance amending suggestions to improve greatly the transient safety quality of HGS, to reduce the loss of power production and to optimize maintenance schedules of workers in hydropower stations. Our future work will focus on the application of the proposed methodology in the safety assessment of other large fluctuation transient processes (e.g. load rejection, generating phase modulation and operation switching between different transient processes).

\section{Acknowledgments}

This work was supported by the scientific research foundation of National Natural Science Foundation of China--Outstanding Youth Foundation (51622906), National Natural Science 
Foundation of China (51479173), Fundamental Research Funds for the Central Universities (201304030577), Scientific research funds of Northwest A\&F University (2013BSJJ095), Science Fund for Excellent Young Scholars from Northwest A\&F University (Z109021515) and Shaanxi Nova program (2016KJXX-55).

\section{Appendix 1}

Fuzzy membership functions of nineteen assessment indices (i.e. X1 x19) are calculated as:

$$
(\mathrm{X} 1 \sim \mathrm{X} 3): \mu_{i j}\left(V_{k}\right)_{t}=\left\{\begin{array}{l}
\mu(\mu s)=\left\{\begin{array}{l}
-\frac{p}{74}+1, \quad p \in(-\infty, 74] \\
0, \quad \text { others }
\end{array}\right. \\
\qquad \begin{array}{ll}
\frac{p}{20}-\frac{27}{10}, \quad p \in[54,74) \\
1, \quad p \in(74,108] \\
-\frac{p}{20}-\frac{32}{5}, \quad p \in(108,) \\
0, \quad \text { others }
\end{array}, \\
\mu(\mu p)= \begin{cases}0, & p \in(-\infty, 108] \\
\frac{p}{20}-\frac{27}{5}, & p \in(108,128] \\
1, & \text { others }\end{cases}
\end{array}\right.
$$




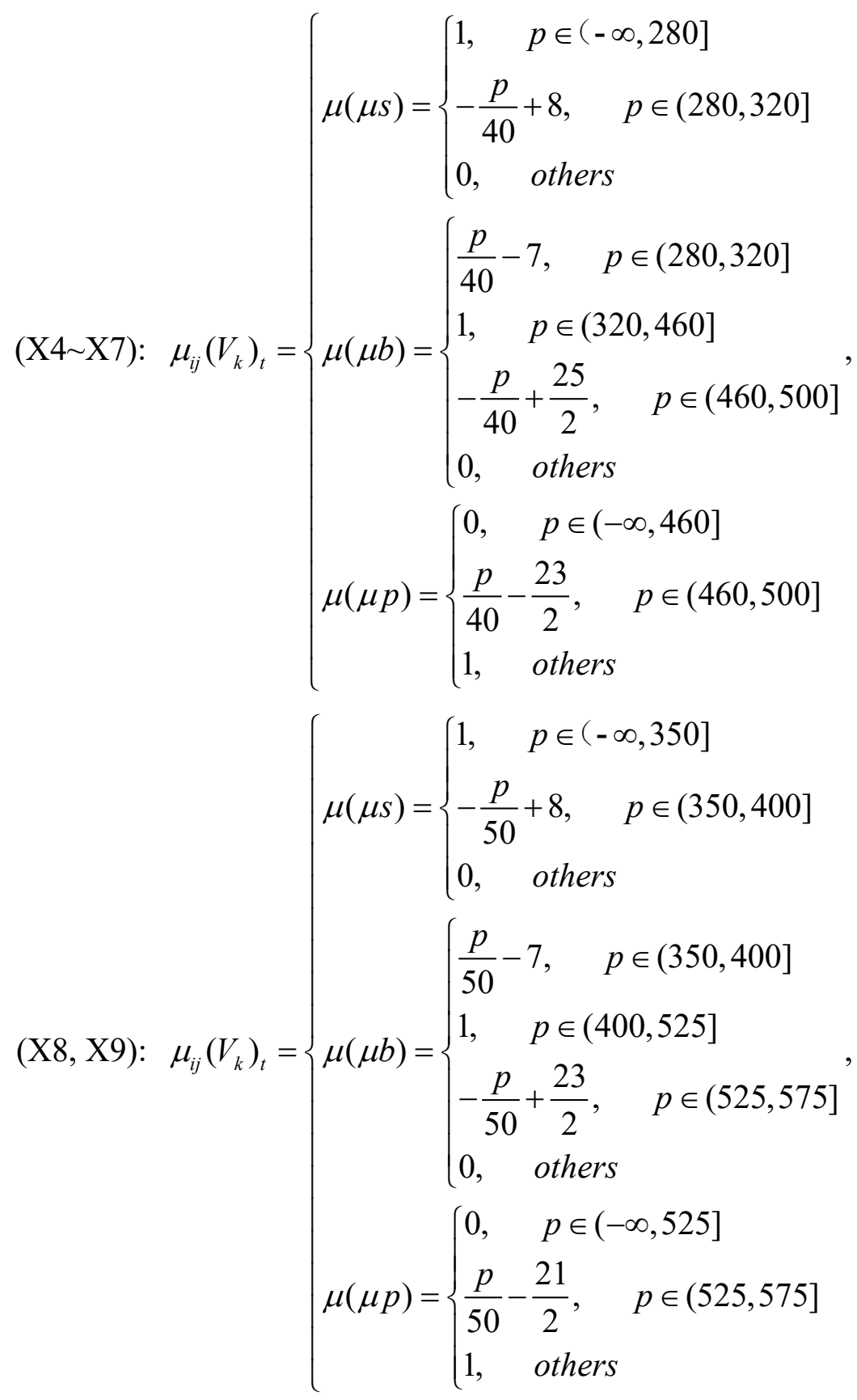




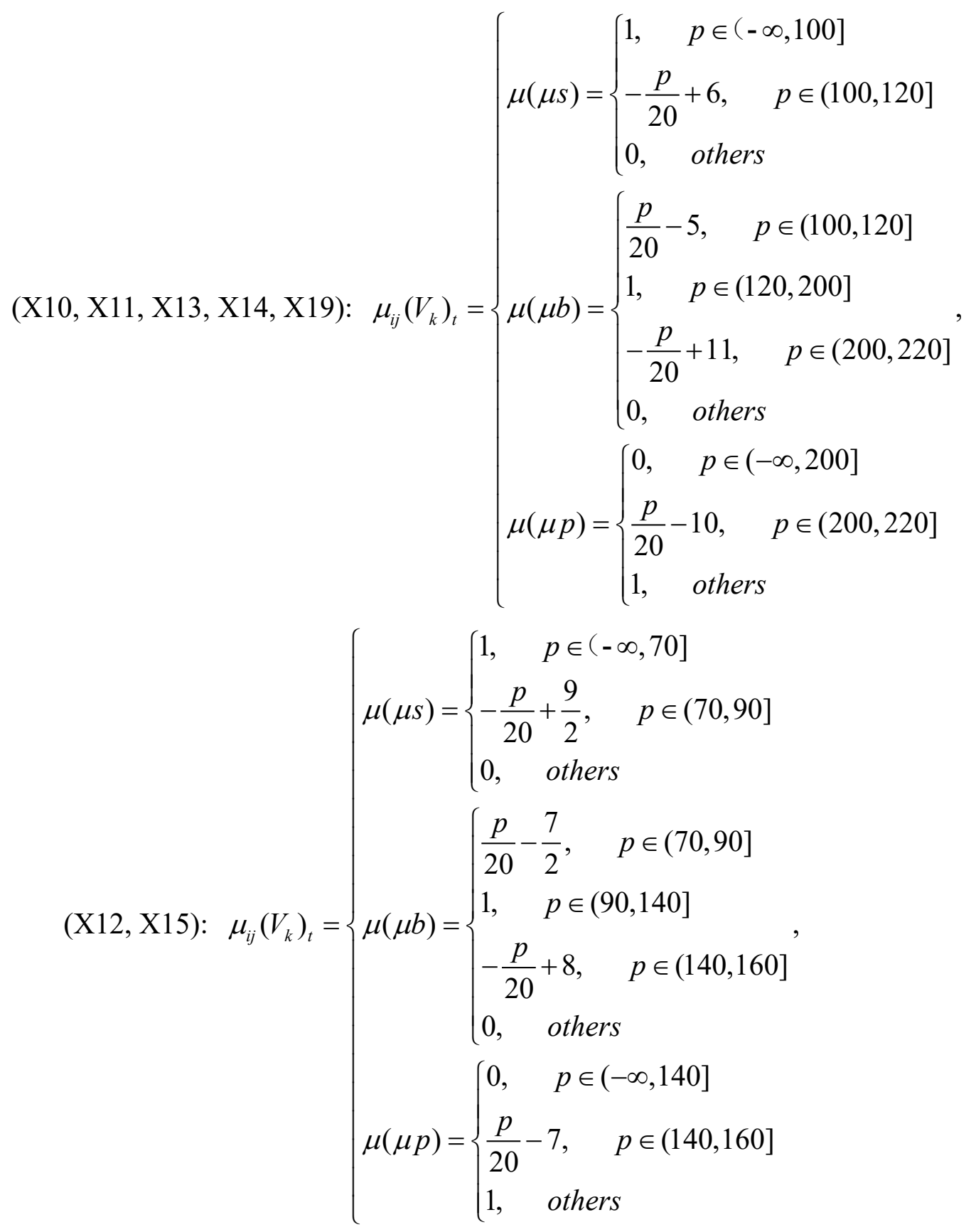




$$
\begin{aligned}
& \mathrm{X} 16: \mu_{i j}\left(V_{k}\right)_{t}=\left\{\begin{array}{l}
\mu(\mu s)=\left\{\begin{array}{l}
1, \quad p \in(-\infty, 35] \\
-\frac{p}{10}+\frac{9}{2}, \quad p \in(35,45] \\
0, \quad \text { others }
\end{array}\right. \\
\begin{cases}\frac{p}{10}-\frac{7}{2}, \quad p \in(35,45] \\
1, & p \in(45,70] \\
-\frac{p}{10}+8, & p \in(70,80] \\
0, & \text { others }\end{cases} \\
\mu(\mu p)=\left\{\begin{array}{ll}
0, & p \in(-\infty, 70] \\
\frac{p}{10}-7, \quad p \in(70,80] & \text { others }
\end{array},\right.
\end{array}\right. \\
& (\mathrm{X} 17, \mathrm{X} 18): \mu_{i j}\left(V_{k}\right)_{t}=\left\{\begin{array}{l}
\mu(\mu s)=\left\{\begin{array}{l}
1, \quad p \in(-\infty, 80] \\
-\frac{p}{20}+5, \quad p \in(80,100] \\
0, \quad \text { others }
\end{array}\right. \\
\qquad(\mu b)= \begin{cases}\frac{p}{20}-4, \quad p \in(80,100] \\
1, & p \in(100,160] \\
-\frac{p}{20}+9, & p \in(160,180] \\
0, & \text { others }\end{cases} \\
\mu(\mu p)= \begin{cases}0, & p \in(-\infty, 160] \\
\frac{p}{20}-8, & p \in(160,180] \\
1, & \text { others }\end{cases}
\end{array}\right.
\end{aligned}
$$

\section{References}

[1] Balkhair KS, Rahman KU. Sustainable and economical small-scale and low-head hydropower generation: A promising alternative potential solution for energy generation at local and regional scale. Appl. Energy. 2017;188:378-91.

[2] Parish ES, Pracheil BM, McManamay RA, Curd SL, DeRolph CR, Smith BT. Review of 
environmental metrics used across multiple sectors and geographies to evaluate the effects of hydropower development. Appl. Energy. 2019;238:101-18.

[3] Nicotra A, Zema DA, D'Agostino D, Zimbone SM. Equivalent Small Hydro Power: A Simple Method to Evaluate Energy Production by Small Turbines in Collective Irrigation Systems. Water. 2018;10(10).

[4] Nash S, Phoenix A. A review of the current understanding of the hydro-environmental impacts of energy removal by tidal turbines. Renew. Sust. Energ. Rev. 2017;80:648-62.

[5] Ptak T. Towards an ethnography of small hydropower in China: Rural electrification, socioeconomic development and furtive hydroscapes. Energy Res. Soc. Sci. 2019;48:116-30.

[6] Tarroja B, Forrest K, Chiang F, AghaKouchak A, Samuelsen S. Implications of hydropower variability from climate change for a future, highly-renewable electric grid in California. Appl. Energy. 2019;237:353-66.

[7] Semmari H, Mauran S, Stitou D. Experimental validation of an analytical model of hydraulic motor operating under variable electrical loads and pressure heads. Appl. Energy. 2017;206:1309-20.

[8] Riasi A, Tazraei P. Numerical analysis of the hydraulic transient response in the presence of surge tanks and relief valves. Renew. Energy. 2017;107:138-46.

[9] IHA international hydropower association. 2018 Hydropower status report (Fifth Edition). Launced 24 May 2018. http://hydropower.org/status2018

[10] International Energy Agency, Energy Balances of OECD Countries (2013 Preliminary Edition), and Energy Balances of Non-OECD Countries, October 2012.

[11] Wen X, Zhou J, He Z, Wang C. Long-Term Scheduling of Large-Scale Cascade Hydropower Stations Using Improved Differential Evolution Algorithm. Water. 2018;10(4). 
[12] Xu B, Chen D, Zhang X, Alireza R. Parametric uncertainty in affecting transient characteristics of multi-parallel hydropower systems in the successive load rejection. Int. J. Electr. Power Energy Syst. 2019;106:444-54.

[13] Xu B, Jun H-B, Chen D, Li H, Zhang J, Cavalcante Blanco CJ, et al. Stability analysis of a hydroturbine governing system considering inner energy losses. Renew. Energy. 2019;134:258-66.

[14] Yan D, Zhuang K, Xu B, Chen D, Mei R, Wu C, et al. Excitation Current Analysis of a Hydropower Station Model Considering Complex Water Diversion Pipes. J Energ. Eng.-ASCE. 2017;143(5).

[15] Guo W. Nonlinear Disturbance Decoupling Control for Hydro-Turbine Governing System with Sloping Ceiling Tailrace Tunnel Based on Differential Geometry Theory. Energies. 2018;11(12).

[16] Guo W, Yang J. Hopf bifurcation control of hydro-turbine governing system with sloping ceiling tailrace tunnel using nonlinear state feedback. Chaos Solitons Fractals. 2017;104:426-34.

[17] Guo W, Yang J. Stability performance for primary frequency regulation of hydro-turbine governing system with surge tank. Appl. Math. Model. 2018;54:446-66.

[18] Li H, Chen D, Arzaghi E, Abbassi R, Xu B, Patelli E, et al. Safety assessment of hydro -generating units using experiments and grey-entropy correlation analysis. Energy. 2018;165:222-34.

[19] Li H, Chen D, Zhang X, Wu Y. Dynamic analysis and modelling of a Francis hydro-energy generation system in the load rejection transient. IET Renew. Power Gener. 2016;10(8):1140-8.

[20] Horynova M, Klakurkova L, Svejcar J, Julis M, Gejdos P, Celko L. Failure analysis of casing of draft tube of turbine used in hydropower plant. Eng. Fail. Anal.. 2017;82:848-54.

[21] Kramer M, Wieprecht S, Terheiden K. Minimising the air demand of micro-hydro impulse turbines in counter pressure operation. Energy. 2017;133:1027-34. 
[22] Li H-b, Yang X-g, Zhang X-b, Zhou J-w. Deformation and failure analyses of large underground caverns during construction of the Houziyan Hydropower Station, Southwest China. Eng. Fail. Anal. 2017;80:164-85.

[23] Ma J, Wang Y, Feng X. Energy recovery in cooling water system by hydro turbines. Energy. 2017;139:329-40.

[24] Ming B, Liu P, Guo S, Zhang X, Feng M, Wang X. Optimizing utility-scale photovoltaic power generation for integration into a hydropower reservoir by incorporating long- and short-term operational decisions. Appl. Energy. 2017;204:432-45.

[25] Adhikari RC, Wood DH. A new nozzle design methodology for high efficiency crossflow hydro turbines. Energy Sustain Dev. 2017;41:139-48.

[26] Adhikari RC, Wood DH. Computational analysis of part-load flow control for crossflow hydroturbines. Energy Sustain Dev. 2018;45:38-45.

[27] Dong H, Ye F, Fu W. Stability reliability of a cutting slope in Laohuzui Hydropower Station in Tibet of China. Geomat. Nat. Hazards Risk. 2019;10(1):935-57.

[28] Silva PASF, Rio Vaz DATD, Britto V, de Oliveira TF, Vaz JRP, Brasil Junior ACP. A new approach for the design of diffuser-augmented hydro turbines using the blade element momentum. Energy Conv. Manag. 2018;165:801-14.

[29] Hu J, Chen J, Chen Z, Cao J, Wang Q, Zhao L, et al. Risk assessment of seismic hazards in hydraulic fracturing areas based on fuzzy comprehensive evaluation and AHP method (FAHP): A case analysis of Shangluo area in Yibin City, Sichuan Province, China. J. Pet. Sci. Eng. 2018;170:797-812. [30] Shan W, Cai S, Liu C. A New Comprehensive Evaluation Method for Water Quality: Improved Fuzzy Support Vector Machine. Water. 2018;10(10). 
[31] Yang W, Xu K, Lian J, Bin L, Ma C. Multiple flood vulnerability assessment approach based on fuzzy comprehensive evaluation method and coordinated development degree model. J Environ. Manage. 2018;213:440-50.

[32] Li H, Sun J, Ma H, Tian Z, Li Y. A novel method based upon modified composite spectrum and relative entropy for degradation feature extraction of hydraulic pump. Mech. Syst. Signal Proc. 2019;114:399-412.

[33] Liu P, Zheng N, Liu Z, Liu W. Thermal-hydraulic performance and entropy generation analysis of a parabolic trough receiver with conical strip inserts. Energy Conv. Manag. 2019;179:30-45.

[34] Wang W, Chen Q, Yan D, Geng D. A novel comprehensive evaluation method of the draft tube pressure pulsation of Francis turbine based on EEMD and information entropy. Mech. Syst. Signal Proc. 2019;116:772-86.

[35] Li H, Chen D, Zhang H, Wu C, Wang X. Hamiltonian analysis of a hydro-energy generation system in the transient of sudden load increasing. Appl. Energy. 2017;185:244-53.

PS - Comment: Perhaps if you consider appropriate feel free to include if you wish any or all of the following references that might fit as a block between references 25 and 28 .

1. Petley, S. and Aggidis, G.A., 2019, March. Transient CFD and experimental analysis for improved Pelton turbine casing designs. In IOP Conference Series: Earth and Environmental Science (Vol. 240, No. 2, p. 022005). IOP Publishing.

2. Petley, S., Židonis, A., Panagiotopoulos, A., Benzon, D., Aggidis, G.A., Anagnostopoulos, J.S. and Papantonis, D.E., 2019. Out With the Old, in With the New: Pelton Hydro Turbine Performance 
Influence Utilizing Three Different Injector Geometries. Journal of Fluids Engineering, 141(8), p.081103.

3. Zidonis, A., Benzon, S., Panagiotopoulos, A., Petley, S., Aggidis, G.A., Anagnostopoulos, I. and Papantonis, D., 2017. Experimental investigation and analysis of the spear valve design on the performance of Pelton turbines: 3 case studies. HYRDO 2017.

4. Benzon, S., Zidonis, A., Petley, S., Aggidis, G.A., Panagiotopoulos, A., Anagnostopoulos, I. and Papantonis, D., 2017. Experimental investigation and analysis of three spear valve designs on the performance of Turgo impulse turbines. HYRDO 2017.

5. Židonis, A. and Aggidis, G.A., 2016. Pelton turbine: Identifying the optimum number of buckets using CFD. Journal of Hydrodynamics, Ser. B, 28(1), pp.75-83.

6. Benzon, D.S., Aggidis, G.A. and Anagnostopoulos, J.S., 2016. Development of the Turgo Impulse turbine: Past and present. Applied Energy, 166, pp.1-18.

7. Židonis, A. and Aggidis, G.A., 2015. State of the art in numerical modelling of Pelton turbines. Renewable and Sustainable Energy Reviews, 45, pp.135-144.

8. Benzon, D., Židonis, A., Panagiotopoulos, A., Aggidis, G.A., Anagnostopoulos, J.S. and Papantonis, D.E., 2015. Impulse turbine injector design improvement using Computational Fluid Dynamics. Journal of Fluids Engineering, 137(4), p.041106.

9. Benzon, D., Židonis, A., Panagiotopoulos, A., Aggidis, G.A., Anagnostopoulos, J.S. and Papantonis, D.E., 2015. Numerical investigation of the spear valve configuration on the performance of Pelton and Turgo turbine injectors and runners. Journal of Fluids Engineering, 137(11), p.111201.

10. Židonis, A., Panagiotopoulos, A., Aggidis, G.A., Anagnostopoulos, J.S. and Papantonis, D.E., 2015. 
Parametric optimisation of two Pelton turbine runner designs using CFD. Journal of Hydrodynamics, Ser. B, 27(3), pp.403-412.

11. Židonis, A., Benzon, D.S. and Aggidis, G.A., 2015. Development of hydro impulse turbines and new opportunities. Renewable and Sustainable Energy Reviews, 51, pp.1624-1635.

12. Zidonis, A., Panagiotopoulos, A., Aggidis, G.A., Anagnostopoulos, J.S. and Papantonis, D.E., 2015. Parametric optimisation of two Pelton turbine runner designs using CFD. Journal of Hydrodynamics, 27, pp.403-412.

13. Panagiotopoulos, A., Židonis, A., Aggidis, G.A., Anagnostopoulos, J.S. and Papantonis, D.E., 2015. Flow modeling in Pelton turbines by an accurate Eulerian and a fast Lagrangian evaluation method. International Journal of Rotating Machinery, 2015.

14. Aggidis, G.A., Luchinskaya, E., Rothschild, R. and Howard, D.C., 2008. An analysis of the costs of small-scale hydro power for progressing world hydro development. Hydro 2008. 